\title{
Bibliografia Portuguesa SOBRE GEORG SIMMEL
}

Organizada por Francisco Felizol Marques e Teresa Dugos

\section{Traduções}

A Metrópole e a Vida do Espírito, in Cidade, Cultura e Globalização, org. Carlos Fortuna, 1997; 2. ${ }^{\mathrm{a}}$ ed., Oeiras: Celta, 2001.

Cultura Feminina: Um livro da série Cultura contemporânea, trad. A. de Aguiar, Galeria Panorama, Dafundo: Bertrand, Lisboa, 1969.

Fidelidade e Gratidão e Outros Textos, trad. Maria João Costa Pereira e Michael Knoch, Lisboa: Relógio D’Água, 2004.

Filosofia da Moda e Outros Escritos, trad. Artur Morão, Lisboa: Texto \& Grafia, 2008.

Filosofia da Paisagem; Os Alpes, apresent. e trad. Adriana Veríssimo Serrão, in Filosofia da Paisagem. Uma Antologia, Lisboa: Centro de Filosofia da Universidade de Lisboa, 2011, pp. 39-58.

Fragmento sobre o Amor e Outros Textos, trad. Maria João Costa Pereira, Lisboa: Relógio d'Água, 2004.

Ideias Religiosas Fundamentais e Ciência Moderna, trad. Artur Morão, Covilhã: Lusosophia press, 2008.

Problemas Fundamentais da Filosofia, trad. Inah Aguiar, Coimbra: Atlântida Editora, 1970.

Psicologia do Dinheiro e Outros Ensaios, trad. Artur Morão, Lisboa: Texto \& Grafia, 2009.

Roma. Uma análise estética; Florença; Veneza, trad. António Sousa Ribeiro, in Revista Crítica de Ciências Sociais (67), 2003, 109-127.

Simmel: A Estética e a Cidade, org. e int. Carlos Fortuna, trad. António Sousa Ribeiro, Coimbra: Imprensa da Universidade, 2010. 


\section{Estudos}

Felizol Marques, Francisco, A Tragédia da Liberdade na Filosofia do Dinheiro de Georg Simmel, Dissertação de Mestrado, Faculdade de Letras da Universidade de Lisboa, 2011.

Fortuna, Carlos, "Narrativas sobre a metrópole centenária: Simmel, Hessel e Seabrook", in Cadernos Metrópole, São Paulo, 13, n. 26, Jul / Dez (2011), 379-93.

Fortuna, Carlos, "Simmel e as Cidades Históricas Italianas: uma Introdução", in Revista Crítica de Ciências Sociais, Coimbra, 67 (2013), 101-127.

Fortuna, Carlos, "Simmel: A metrópole e a alegoria da ruína", in Robert Pechman (org.), Rio de Janeiro: UFRJ (no prelo).

Garcia, José Luís, "Sobre as Origens da Crítica da Tecnologia na Teoria Social. A Visão Pioneira e Negligenciada da Autonomia da Tecnologia de Georg Simmel", in Dilemas da Civilização Tecnológica, eds. Hermínio Martins e José Luís Garcia, Lisboa: Imprensa de Ciências Sociais, 2003, pp. 91-138.

Garcia, José Luís, "Simmel on Culture and Technology <http://www.ics. ul.pt/rdonweb-docs/2005_Simmel\%20Studies.pdf>“, Simmel Studies, Jg 15, 2/2005, Bielefeld: Universität Bielefeld, pp.123-178. ISSN: 1616-2552.

Garcia, José Luís, 2, "Sobre as origens da crítica da tecnologia na teoria social: Georg Simmel e a autonomia da tecnologia", in Scientia Studia: Revista Latino-Americana de Filosofia e História da Ciência, São Paulo vol. 5, n. 3 (Julho-Setembro 2007), 287-336. ISSN: 1678-3166

Garcia, José Luís, "Cultura y tecnologia en Georg Simmel", in Georg Simmel. Una Revisión Contemporánea, coord. Olga Sabido Ramos, Barcelona: Anthropos Editorial, 2009, 290-314.

Luís, Joana Quaresma, "Jankélévitch, leitor de Simmel”, Philosophica, Lisboa, 32 (2008), 31-52.

Mendes, João Paulo Cruz, "Indivíduo e Realidade: de Simmel a Kracauer", Philosophica 27 (2006), 135-155.

Morão, Artur, Aspectos da Hermenêutica do Dinheiro em Georg Simmel, Centro de Estudos de Filosofia/Faculdade de Ciências Humanas/ Universidade Católica Portuguesa, Lisboa, 2011.

Ramos, José Artur, $O$ Auto-Retrato ou a Reversibilidade do Rosto, Dissertação de Mestrado, Faculdade de Letras da Universidade de Lisboa, 2001.

Ramos, José Artur, Retrato: o Desenho da Presença, Dissertação de Doutoramento, Faculdade de Belas Artes da Universidade de Lisboa, 2007. 
Roberto, Paulo Frazão, 2007, "A harmoniosa pregnância vital da paisagem natural em Georg Simmel”, Philosophica 29 (2007), 65-85.

Sousa Fernandes, Teresa, "Da metáfora à construção sociológica: A ideia de centralidade nas teorias de Émile Durkheim e Georg Simmel", Actas do II Congresso Português de Sociologia, Volume II, Lisboa: Editorial Fragmentos e Associação Portuguesa de Sociologia, 1992, pp. 504-518,

Sousa Fernandes, Teresa, 1993, "Assimetria dos sexos e construção do mundo social na teoria de Georg Simmel", in Sociologia. Problemas e Práticas, n. ${ }^{\circ} 13$ (1993), Centro de Investigação e Estudos de Sociologia (CIES), Lisboa, 19-38.

Serrão, Adriana Veríssimo, "Sentimento da Natureza e Imagem do Homem: Kant - Feuerbach - Simmel", Philosophica 30 (2007), Lisboa, 203-224 .

Serrão, Adriana Veríssimo, 2011, "La nature retrouvée à travers le paysage", in Actas do Colóquio "ACT 21 - Naturalismo(s)", org. Kelly Basílio, Lisboa, Faculdade de Letras, Centro de Estudos Comparatistas, pp. 59-74.

Serrão, Adriana Veríssimo, "Pensar a natureza e trazer a paisagem à cidade", in Psicologia Social e Imaginário, coord. Sandra Patrício Vichietti, São Paulo: Ed. Zagodoni, 2012, pp. 61-71. 